\title{
FUNDAMENTOS TEÓRICOS PARA A AVALIAÇÃO ESCOLAR FRENTE À INCLUSÃO DE ALUNOS COM DEFICIÊNCIA MENTAL: da prática autoritária para a prática inclusiva
}

\author{
Giovani Ferreira Bezerra (G-PIBIC/UEMS) \\ Dr ${ }^{a}$. Doracina Aparecida de Castro Araujo (UEMS)
}

\begin{abstract}
Resumo
O atual modelo de avaliação da aprendizagem escolar praticado na maioria das escolas regulares caracteriza-se por ser autoritário, disciplinador e de orientação meramente quantitativa. Entretanto, tal modelo revela-se insuficiente e insustentável, sobretudo diante da inclusão de alunos com deficiência mental nas salas de aula comuns, pois estes estarão sempre em desvantagem em relação ao formalismo antipsicológico dos critérios tradicionais. Assim, surge a necessidade urgente de se articular e divulgar novos princípios que contemplem uma prática avaliativa dinâmica, qualitativa e inclusiva. É exatamente este o objetivo do presente trabalho, que, para tanto, buscou na pesquisa bibliográfica os fundamentos teóricos. Pela pesquisa, pôde-se perceber que os conceitos de Vygotsky $^{1}$ sobre Zona de Desenvolvimento Proximal, Aproveitamento Escolar Absoluto e Aproveitamento Escolar Relativo são os que mais podem orientar os professores, neste momento, quanto à correta verificação da aprendizagem escolar de todos os seus alunos, pois abrem espaço para uma perspectiva de avaliação totalizante, processual e consciente da singularidade cognitiva e psicológica que envolve a personalidade de cada educando. Estes conceitos lhes darão, assim, condições para refletir também sobre as conquistas de cada criança, e não apenas para condená-la por seus eventuais fracassos, supostamente apontados por notas frias, cúmplices de uma rígida burocracia escolar e dissociadas de qualquer trabalho analítico cuidadoso.
\end{abstract}

Palavras-chave: Avaliação da Aprendizagem Escolar. Inclusão de Crianças com Deficiência Mental. Zona de desenvolvimento Proximal. Aproveitamento escolar absoluto. Aproveitamento escolar Relativo.

\section{Introdução}

Parece quase unânime entre os educadores e estudiosos da educação que uma das questões mais árduas e tensas do processo educativo é, sem dúvida, a avaliação escolar. O consenso, entretanto, para por aí, já que há diversas orientações pedagógicas que buscam propor maneiras bastante díspares entre si no que tange à amenização desse "problema", isto é, na proposição de meios e alternativas para a elaboração, correção e interpretação de uma avaliação escolar.

\footnotetext{
${ }^{1}$ Há variações quanto à grafia do nome deste autor. Por isso, quando se tratar de citações, manteremos a escrita original da fonte consultada e, nos demais casos, para efeitos de padronização, adotaremos a forma Vygotsky, bastante popular entre os pesquisadores brasileiros.
}

\begin{tabular}{|l|l|l|l|l|l|}
\hline Interface da Educ. & Paranaíba & v. 1 & n. 1 & p. 83-94 & 2010 \\
\hline
\end{tabular}


Em tal cenário multiforme e eclético não é raro o vai-e-vem de modismos e arbitrariedades por parte daqueles que a concebem e a aplicam, devido à falta de uma análise crítica do modelo avaliativo que, supostamente acompanhando tendências inovadoras e progressistas, decidem adotar. Como notável consequência, o uso da avaliação, esse importante instrumento pedagógico, continua repleto de indefinições e incompreensões, esvaziando-se cada vez mais do seu sentido e finalidades originais.

Este artigo pretende, então, discutir criticamente o significado atual predominante da prática avaliativa para, em seguida, apresentar, dentre tantas perspectivas teóricas sobre o assunto que tem emergido nos últimos anos, aquela que nos parece a mais consistente e oportuna para o reencaminhamento dessa prática, sobretudo diante dos recentes desafios a serem enfrentados pelos professores com a inclusão de alunos com deficiência mental nas escolas regulares. De todas as deficiências, sem dúvida, esta é a que mais "perturba" o cotidiano escolar, solicitando incontinênti uma redefinição paradigmática da maneira tradicional de avaliar. É, pois, nessa direção que pretendemos conduzir as reflexões do presente texto.

\section{Avaliação Escolar: um quadro de horrores}

Antes de propormos qualquer alteração significativa no modo atual de avaliar que se pratica na maioria das escolas regulares brasileiras, precisamos, primeiramente, compreendê-lo em suas linhas gerais, ressaltando os seus aspectos mais marcantes e hegemônicos. Somente depois desse trabalho, é possível esboçar as diretrizes de uma ação pedagógica transformadora a respeito de nossa temática.

A princípio, recorremos a Luckesi, um dos autores brasileiros que mais tem estudado sobre a avaliação da aprendizagem escolar e evidenciado, com intenso realismo, as mazelas que comumente a envolvem e a desvirtuam de seu verdadeiro significado. De acordo com o estudioso, o sentido real da avaliação não poderia ser outro senão entendê-la como "[...] pausa para pensar a prática e retornar a ela” (LUCKESI, 2006, p. 34), um “[...] 'momento de fôlego' na escalada, para, em seguida, ocorrer a retomada da marcha de forma mais adequada, e nunca um ponto definitivo de chegada [...]" (LUCKESI, 2006, p. 34-35).

A realidade, como se sabe, processa-se de maneira bastante oposta e antagônica. O mesmo autor reconhece que a avaliação tem se caracterizado, sobretudo, por seu viés

\begin{tabular}{|l|l|l|l|l|l|}
\hline Interface da Educ. & Paranaíba & v. 1 & n. 1 & p3-94 & 2010 \\
\hline
\end{tabular}


antidemocrático, classificatório, disciplinador e ameaçador, compondo um inegável quadro de horrores. Ela se apresenta, de fato, como um verdadeiro mecanismo de punição, controle e vingança que o professor utiliza contra seus alunos. Dessa feita, o resultado é uma inversão muito clara do seu papel. Conforme cita Luckesi (2006, p. 40), "De instrumento de diagnóstico para o crescimento, a avaliação passa a ser um instrumento que ameaça e disciplina os alunos pelo medo".

$\mathrm{Na}$ esteira dessas considerações, Vygotsky (2004) também se posiciona contra tal procedimento "pedagógico", entendido por ele como antipsicológico, uma vez que perturba e desestabiliza todas as reações emocionais dos alunos, de forma que a avaliação, praticada nesses moldes, nunca mostra as reais potencialidades dos sujeitos avaliados. O medo inibe a manifestação das respostas conscientes e intencionais e, assim, produz "[...] um quadro totalmente falso e deformado do comportamento [...]" (VIGOTSKI, 2004, p. 87), atuando, na maioria das vezes, “[...] como elemento rebaixador e deturpador sobre os sistemas de reprodução das reações" (VIGOTSKI, 2004, p. 87-88) em cada educando.

Ditas de outro modo, essas palavras de Vygotsky nos chamam a atenção para o fato inegável de que o medo funciona como agente limitante da cognição humana e da expressão mais autêntica das possibilidades de cada sujeito e, por isso mesmo, compromete o resultado de qualquer processo avaliativo que nele se apoie. Sendo assim, parodiando este autor, podemos afirmar que existe uma interação dialética entre as dimensões intelectual e afetiva ou emocional de cada pessoa (VYGOTSKI, 1997). A qualidade dessa interação acaba interferindo na forma como os educandos se posicionam perante os testes escolares: se de maneira positiva e autônoma, ou, ao contrário, de forma negativa e temerosa. Obviamente, esta última forma é a mais comum em nossa realidade pedagógica, ainda atrelada ao autoritarismo e ao tradicionalismo passadistas.

Continuando nosso raciocínio, podemos salientar também que outra lamentável característica do processo avaliativo é seu absoluto referencial quantitativo. Com isso, a esperada reflexão autêntica entre os sujeitos nele envolvidos - educadores e educandos - sobre o que foi assimilado, vivenciado e compartilhado durante as aulas é substituída pela angustiante preocupação com a nota.

Quanto a este fato, Hoffmann, outra estudiosa do assunto, afirma que, nessa busca incessante pela nota, a avaliação fica descaracterizada, reduzida “[...] a uma prática de registro de

\begin{tabular}{|l|l|l|l|l|l|}
\hline Interface da Educ. & Paranaíba & v. 1 & n. 1 & p. 83-94 & 2010 \\
\hline
\end{tabular}


resultados acerca do desempenho do aluno em um determinado período do ano letivo" (HOFFMANN, 2000, p. 27).

Assim, longe de ser o momento de retorno crítico à prática e uma oportunidade para fomentá-la, ela impõe-se como inquestionável "[...] momento terminal do processo educativo [...]" (HOFFMANN, 2000, p. 20).

Assim, depois dessas breves considerações sobre o assunto, pode-se afirmar que o modelo avaliativo descrito não pode nem possui competência teórico-prática para continuar hegemônico no meio escolar. É mister fugir o quanto antes do esquema autoritário que ele encerra, o que implica, em contrapartida, retirar o professor da cadeira de juiz arbitrário na qual ele tem se assentado e recolocá-lo na sua posição original de mediador, articulador precioso de novas aprendizagens recíprocas ou colaborativas. Mas, evidentemente, não há como fazer isso, caso não se reconstrua também o significado da ação avaliativa, que, para Hoffmann (2000, p. 32), poderia ser traduzido por uma "[...] ação avaliativa de acompanhamento permanente do desenvolvimento do educando $[\ldots] "$.

Redefinições assim são de grande necessidade, em particular neste momento histórico em que as escolas se abrem para a diversidade humana, o que por si só inviabiliza a aplicação dos tradicionais procedimentos avaliativos, uma vez que é preciso considerar as necessidades educacionais de cada ser humano. Ora, tais procedimentos sempre estiveram comprometidos com a classificação dos educandos, com a sua seletividade social e com a homogeneização forçada dos seus modos de aprender e objetivar os conteúdos didáticos trabalhados (LUCKESI, 2006). Contudo, basta colocarmo-nos diante de um aluno com deficiência mental para vermos como esta deficiência põe em xeque a forma conservadora de avaliar, exigindo, de imediato, critérios avaliativos e formulações teórico-filosóficas mais coerentes com o novo cenário escolar. Por isso, achamos imprescindível abordar mais detidamente essas questões a seguir.

\section{Avaliação Escolar: a caminho de uma prática revolucionária}

Em verdade, com a inclusão de alunos com deficiência mental (e também outras deficiências), estas antigas "violências", arbitrariedades e "torturas psicológicas" comuns ao ato de avaliar devem ser abandonadas com toda certeza, não só porque são exemplos marcantes e triste da intolerância, abuso de autoridade e coerção ainda praticados em sala de aula por grande

\begin{tabular}{|l|l|l|l|l|c|}
\hline Interface da Educ. & Paranaíba & v. 1 & n. 1 & p. 83-94 & 2010 \\
\hline
\end{tabular}


parte dos professores (não todos, é claro!), como também pelo fato inegável de que, com a continuidade de tal modelo, aqueles alunos sofrerão um impacto ainda mais negativo em sua aprendizagem, na comparação com os demais.

Eles não têm estrutura psicológica e cognitiva para "funcionar" sob a pressão, o medo e a angústia que as provas e os exames costumam trazer à classe toda. Seus mecanismos de defesa são frágeis e mais vulneráveis. Segundo Griboiédov (apud VYGOTSKI, 1997, p. 34, tradução nossa), as crianças com deficiência mental apresentam "[...] reduzida capacidade de resistir às influências desfavoráveis, fadiga elevada e tendência à exaustão [...]”.

Desse modo, o professor deve assumir maior flexibilidade, ser mais criativo, democrático e consciente de seu papel na avaliação, respeitando o ritmo e a singularidade de cada educando. Para tanto, Batista e Mantoan sugerem o abandono da prática discriminatória e coercitiva em nome de uma prática inclusiva, ressaltando, todavia, que isso significa uma “[...] verdadeira revolução, que implica em inovações na forma de o professor e o aluno avaliarem o processo de ensino e aprendizagem" (BATISTA; MANTOAN, 2006, p. 14, grifo nosso). Revolução, explicam as autoras, porque "[...] desmonta de uma só vez o caráter homogeneizador da aprendizagem e elimina todas as demais características excludentes das escolas comuns que adotam propostas pedagógicas conservadoras" (BATISTA; MANTOAN, 2006, p. 14).

Tal revolução, entretanto, carece de uma base teórica sólida e apta a contemplar deveras as exigências de uma prática inclusiva. Com nossas pesquisas, acreditamos tê-la encontrado nas proposições de Vygotsky. Este autor pode melhor nos subsidiar na formulação de uma proposta de avaliação dinâmica, interativa e capaz de cumprir, para todos os alunos, sua função mediadora, sem descambar para os riscos da rigidez da "normatividade curricular", expressão que muito a propósito tomamos de empréstimo de Beyer (2006).

Para Vygotsky, a avaliação não é nem deve ser jamais a etapa final da ação docente, como normalmente tem sido e conforme se pode facilmente depreender das palavras de Hoffmann (2000). Ela não é pretexto para um mero e frio registro de dados numéricos requisitados pela burocracia escolar. Ao contrário, "A partir da concepção vygotskiana, a avaliação deve se pautar pela possibilidade da superação" (BEYER, 2006, p. 96). Além disso, este enfoque teórico preconiza que "[...] na avaliação não basta verificar as condições atuais do desempenho escolar da criança.

\begin{tabular}{|l|l|l|l|l|l|}
\hline Interface da Educ. & Paranaíba & v. 1 & n. 1 & p. 83-94 & 2010 \\
\hline
\end{tabular}


Antes, sua condição intelectual somente poderá ser devidamente avaliada quando ocorrerem situações de mediação [...]" (GUTHKE apud BEYER, 2006, p. 94), essenciais ao progresso cognitivo e à correta verificação da aprendizagem escolar em crianças com deficiência mental.

Nesse ponto, vale destacar um notável e já relativamente difundido conceito vygotskiano o qual, ao lado de outros conceitos menos conhecidos que apresentaremos logo mais, muito tem a contribuir conosco no sentido da dar à avaliação escolar os novos contornos paradigmáticos e operacionais de que necessitamos. Trata-se da Zona de Desenvolvimento Proximal, definida por Vygotsky como

[...] a distância entre o nível de desenvolvimento real, que se costuma determinar através da solução independente de problemas e o nível de desenvolvimento potencial, determinado através da solução de problemas sob a orientação de um adulto ou em colaboração com companheiros mais capazes (VIGOTSKI, 2008, p.97, grifo do autor).

O amplo conhecimento teórico da ideia expressa pela Zona de Desenvolvimento Proximal tem sua importância aqui justificada porque esperamos, por meio dela, incentivar os professores a assumir uma postura equilibrada, reflexiva e menos arbitrária no ato de avaliar. De modo geral, este conceito sugere que a verificação da aprendizagem de determinado conteúdo não ocorra apenas em um, mas em dois níveis de atividade intelectual, isto é, a Atividade Mental Individual e a Atividade Mental Colaborativa. Juntas, elas configuram em cada educando uma estrutura cognitiva complexa e em constante expansão, que um simples teste não pode sequer suspeitar.

De fato, as tradicionais provas e exames costumam se preocupar em verificar apenas o nível de desenvolvimento real, ou seja, o conjunto de informações, fórmulas e conhecimentos que os educandos supostamente teriam condições de reproduzir e aplicar, sozinhos, no instante da avaliação, sem qualquer apelo à mediação do professor ou de outros recursos didáticos, "[...] sem a assistência de outros, sem demonstração e sem o fornecimento de pistas" (VIGOTSKI, 2008, p. 99). No entanto, os alunos que não conseguem alcançar o nível de desenvolvimento real no mesmo tempo que o esperado para a sua turma, como as crianças com deficiência mental, saem muito prejudicados com tal sistemática avaliativa unilateral e superficial. Assim, eles acabarão tendo computadas as piores notas ou conceitos perante a classe, fato que só agravará suas dificuldades cognitivas e evidenciará cruelmente suas limitações.

\begin{tabular}{|l|c|c|c|c|c|}
\hline Interface da Educ. & Paranaíba & v. 1 & n. 1 & p. 83-94 & 2010 \\
\hline
\end{tabular}


Por outro lado, quando o professor se utiliza do conceito de Zona de Desenvolvimento Proximal, ele compreende que a avaliação também precisa se basear na promoção e análise das situações de cooperação entre os alunos, para que a Atividade Mental Colaborativa se instaure na sala de aula e se crie um ambiente favorável à aprendizagem, à coautoria do conhecimento e à convivência interpessoal. Nesse caso, ele exerce, então, seu papel de mediador e as crianças com deficiência mental encontram maiores possibilidades para objetivar o que já aprenderam, tomando partido nas atividades iniciadas pelos seus colegas, além de adquirir novas competências intelectuais. No dizer de Vygotsky, "Numa atividade coletiva ou sob a orientação de adultos, usando a imitação, as crianças são capazes de fazer muito mais coisas" (VIGOTSKI, 2008, p. 101) e “[...] o que é absolutamente impossível para um, é possível para dois" (FEUERBACH apud VYGOTSKI, 1997, p. 247, tradução nossa).

Indo um pouco mais a fundo, o autor supracitado chama nossa atenção para alguns cuidados a serem tomados na hora de avaliar honestamente qualquer educando, em especial aqueles com deficiência mental. Segundo ele,

[...] para julgar corretamente as possibilidades de desenvolvimento e o nível real de desenvolvimento de uma criança retardada ${ }^{2}$ é preciso levar em consideração não somente o que ela pode dizer, mas também o grau de sua compreensão. Ora, podemos compreender aquilo que se encontra dentro dos limites da nossa compreensão, mas isso é muito mais do que podemos expressar (VYGOTSKI, 1997, p. 141, tradução nossa).

Logo, aqueles que avaliam - os educadores - deverão estar atentos de múltiplas formas ao verdadeiro potencial dos seus alunos, adotando um olhar mais relativo sobre o resultado das provas e testes. Todavia, é plausível que se perguntem, a esta altura de nossas explicações, como aplicar praticamente os pressupostos vygotskianos com toda a classe na rotina de uma escola regular que ainda exerce, e deve exercer por muito tempo, uma avaliação predominantemente quantitativa, inflexível e burocrática? Em que medida esses pressupostos podem romper com o velho paradigma que denunciamos? Quais os novos critérios e características para uma prática avaliativa inclusiva e acolhedora, além do destaque às situações de trabalho coletivo em sala de aula? Tais interrogações são as que pretendemos responder brevemente a seguir, dentro dos estreitos limites que este artigo nos permite.

\footnotetext{
${ }^{2}$ Vygotsky não usa o termo "retardado" com a intenção depreciativa que o uso popular acabou atribuindo a esta palavra. Por isso, resolvemos mantê-la em nossa tradução, embora hoje se recomende o uso da expressão criança ou pessoa com deficiência mental.
}

Interface da Educ.
Paranaíba
V. 1

\begin{abstract}
n. 1
\end{abstract}

\begin{tabular}{|l|l|l|}
\hline 1 & p. 83-94 & 2010 \\
\hline
\end{tabular}




\section{Avaliação: enfim, um ato amoroso}

Para articular uma proposta de avaliação inclusiva, dinâmica e comprometida com o crescimento intelectual de todos os educandos, vamos recorrer outra vez a Vygotsky, expondo outros dois conceitos seus que ainda são, se são, insuficientemente divulgados entre os professores e mesmo entre os pesquisadores da área. À semelhança do que postulou para a formulação teórica mais genérica da Zona de Desenvolvimento Proximal, o autor recomenda, na análise do aproveitamento escolar propriamente dito, dois indicadores para situar e conferir legitimidade ao percurso avaliativo: o aproveitamento escolar absoluto e o aproveitamento escolar relativo (VIGOTSKI, 2004).

O primeiro deles refere-se ao desempenho quantitativo imediato dos alunos, ao nível individual, e não considera, historicamente, a evolução da aprendizagem que apresentam no decorrer do ano letivo, tomando-se esse período de tempo a título de exemplificação. O outro, por sua vez, permite uma reflexão sobre como se processou a aprendizagem nos alunos, o que de fato puderam aprender, como cada um progrediu em relação a si mesmo e à turma, pressupondo prioritariamente uma abordagem avaliativa que contemple a qualidade do desempenho escolar.

Em decorrência disso, deparamo-nos com uma nova possibilidade de avaliação que se revela promissora principalmente para os estudantes com deficiência mental, uma vez que, se ao nível meramente quantitativo, absoluto, eles acabam por apresentar frequentemente notas ou conceitos inferiores e negativos, isto é, abaixo da média definida pelas escolas regulares (que, como já afirmamos textualmente, ainda se apoiam em perspectivas de avaliação quantitativa e, por isso, é preciso ponderar esse dado objetivo da realidade), o mesmo nem sempre será possível de se dizer quando considerado o aproveitamento relativo. Como recomenda o autor supracitado,

\footnotetext{
Não devemos esquecer uma circunstância decisiva que nos é colocada quando falamos sobre a educação de crianças com atraso profundo. Não nos referimos à importância quantitativa, mas sim a significação qualitativa e a avaliação dos progressos em seu desenvolvimento. [...]. Esta avaliação qualitativa resolve toda a questão (VYGOTSKI, 1997, p. 241, tradução nossa).
}

Nesse caso, é ilustrativo imaginarmos o seguinte exemplo: uma criança com quadro de deficiência mental obtém uma nota 2 em determinada avaliação e, em seguida, alcança uma nota 4. Mesmo permanecendo em níveis numericamente pouco expressivos, devemos observar que factualmente manifestou um avanço duas vezes maior da primeira para a segunda nota e, assim,

\begin{tabular}{|l|l|l|l|l|c|}
\hline Interface da Educ. & Paranaíba & v. 1 & n. 1 & p. 83-94 & 2010 \\
\hline
\end{tabular}


seu aproveitamento relativo, na comparação entre os valores, seria positivo (VIGOTSKI, 2004). Por esta razão, Vygotsky pontua que

O aproveitamento relativo não adquire importância tão grande em parte alguma como na escola para crianças mentalmente retardadas ${ }^{3}$ pois é aqui que estudam as crianças com rendimento negativo absoluto. Em relação a essas crianças é importante levar sempre em conta o aproveitamento relativo. Isto deve estender-se de forma especialmente ampla às escolas para crianças mentalmente retardadas e aplicado ao aproveitamento relativo (VIGOTSKI, 2004, p. 497- 498).

Desse ponto de vista, o professor passa a ter em mãos um recurso para analisar a evolução da aprendizagem dos demais alunos e compará-la com a dos alunos com limitações intelectuais, podendo, inclusive, se surpreender quando proceder a uma análise menos superficial e imediatista. Para esclarecer melhor, consideremos agora um aluno sem qualquer dificuldade de aprendizagem e que, ao contrário, se caracterize pelas boas notas ou conceitos. Em uma primeira avaliação, obtém o valor 10 e, na segunda, 9. Obviamente este é muito superior ao primeiro no critério do desempenho absoluto. Contudo, estaríamos, caso parássemos a análise neste momento, observando somente a aparência do fenômeno. É preciso passar da quantidade à qualidade para desvendar as contradições internas desses valores. Assim, perceberíamos que se trata de um desempenho relativo negativo. $\mathrm{O}$ aluno desacelerou seu ritmo de aprendizagem em quase uma vez (VIGOTSKI, 2004). Por isso, Vygotsky (2004, p. 498) afirma que “[...] frequentemente se revela um aproveitamento relativamente baixo do aluno que está adiante da turma em termos de aproveitamento absoluto".

Portanto, diante do que foi exposto, os professores encontram subsídios para superar suas reservas quanto à avaliação dos alunos com deficiência mental, muitas vezes rotulados a priori como totalmente alheios à aprendizagem escolar, fracassados completos que a grande custo atingirão "média" no final do bimestre, descartando-se, nesse discurso, os eventuais progressos qualitativos que tenham realizado. O aproveitamento relativo desbanca, pois, essa tese fatalista e mostra que os "mais inteligentes" nem sempre estão à frente da turma em todos os aspectos, como suas notas "altas" poderiam sugerir, nem os "mais atrasados" o são em todas as

\footnotetext{
${ }^{3}$ Nesse parágrafo, Vygotsky está considerando o aproveitamento relativo como um recurso avaliativo de grande valia, principalmente para acompanhar o desempenho de crianças com deficiência mental que frequentavam a escola especial. Contudo, pode-se generalizar sua aplicação, sem ferir as ideias do autor, para as escolas regulares inclusivas, que agora também recebem essas crianças em seu quadro de alunos.
}

\begin{tabular}{|l|l|l|l|l|l|}
\hline Interface da Educ. & Paranaíba & v. 1 & n. 1 & p. 83-94 & 2010 \\
\hline
\end{tabular}


circunstâncias. Ele "[...] abre pela primeira vez os olhos do professor para perceber que, entre todos os grupos de crianças com índices de desenvolvimento mental alto, médio e baixo, existem crianças com aproveitamento elevado e aproveitamento baixo" (VIGOTSKI, 2004, p.498-499).

Consequentemente, a avaliação precisa converter-se num instrumento diagnóstico que objetiva o conhecimento do ritmo de avanço, de progresso de cada aluno no entendimento dos conteúdos trabalhados, bem como na retomada crítica daquilo que não pôde ser devidamente compreendido, longe de constituir-se num simples registro numérico de índices absolutos, unilaterais e que, muitas vezes, mascara a realidade e reforça estereótipos do tipo "alunos bons $\mathrm{X}$ alunos ruins; alunos capazes X incapazes". A ela, o professor sempre deve acrescentar o peso do critério relativo, embora deva manter uma prática avaliativa comum a todos os educandos, “[...] para que não sejam feridos os princípios da inclusão escolar" (BATISTA; MANTOAN, 2006, p. $15)$.

Por fim, lançamos um apelo humanista e esperançoso. $\mathrm{O}$ ato de avaliar, sobretudo com a presença de alunos com deficiência mental na escola regular, deve converter-se sem medo em um "[...] ato amoroso, no sentido de que a avaliação, por si, é um ato acolhedor, integrativo, inclusivo" (LUCKESI, 2006, p. 172). E, desse modo, os professores carecem de compreender que “[...] avaliar um aluno com dificuldades é criar a base de como incluí-lo dentro do círculo de aprendizagem" (LUCKESI, 2006, p. 173), base esta que pode concretizar-se mais na valorização de suas habilidades, do que na condenação das suas deficiências e erros. Aí reside a essência da avaliação inclusiva que, humildemente, esperamos despertar na mente de cada educador.

\section{Considerações Finais}

Vimos, segundo algumas pesquisas, que a avaliação da aprendizagem escolar na quase totalidade das escolas regulares se caracteriza, sobretudo, pelo caráter negativo das provas e exames, que, nas mãos da maioria dos professores, tornam-se ferramenta de classificação, controle e manipulação dos alunos. Por isso mesmo, costuma pecar por sua incompletude diagnóstica e pela unilateralidade, isto é, não consegue verificar as reais competências dos educandos, já que, do modo como é aplicada, exclui a possibilidade de outras situações de mediação pedagógica e de trabalho coletivo para a classe.

\begin{tabular}{|l|l|l|l|l|l|}
\hline Interface da Educ. & Paranaíba & v. 1 & n. 1 & p. 83-94 & 2010 \\
\hline
\end{tabular}


Entretanto, diante da inclusão de alunos com deficiência mental nas salas de aula comuns, alertamos para o fato evidente de que tal modelo avaliativo autoritário e burocrático, descompromissado com o verdadeiro crescimento cognitivo dos educandos, não pode mais continuar hegemônico, pois fragiliza principalmente aqueles alunos e expõe ainda mais suas incapacidades perante a turma, obstaculizando-lhes a aprendizagem. Logo, buscamos nas proposições de Vygotsky a consistência teórica para a formulação de alguns fundamentos para uma prática avaliativa dinâmica, inclusiva e totalizante. Nesse trabalho, foram imprescindíveis os conceitos vygotskianos de Zona de Desenvolvimento Proximal e aproveitamento escolar absoluto e relativo.

Por fim, queremos aproveitar estas considerações finais para dizer que temos consciência de que esses conceitos carecem ainda de ser melhor explicados em sua relação didática com a avaliação de crianças com e sem deficiência mental em um estudo mais exaustivo, que por ora não podemos levar a cabo. Além disso, seu uso no cotidiano escolar não poderá prescindir de uma sistematização mais rigorosa e do estabelecimento de critérios mais definidos que esclareçam aos professores como levar em conta, por exemplo, o "peso" do aproveitamento relativo. Mesmo assim, esperamos ter contribuído para uma mudança de perspectiva no que diz respeito à verificação da aprendizagem escolar e deixado claro que avaliar pode ser muito mais do que atribuir notas aos alunos. Pode e precisa ser o momento de uma reflexão amorosa e honesta entre dois sujeitos: quem avalia e quem é avaliado.

\section{Referências}

BATISTA, C. A. M.; MANTOAN, M. T. E. Educação Inclusiva: atendimento educacional especializado para a deficiência mental. Brasília: Ministério da Educação, Secretaria de Educação Especial, 2006.

BEYER, H. O. Inclusão e avaliação no sistema escolar. In: Inclusão e avaliação na escola: de alunos com necessidades educacionais especiais. 2. ed. Porto Alegre: Mediação, 2006.

HOFFMANN, J. M. L. Avaliação: mito e desafio: uma pespectiva construtivista. 29. ed. Porto Alegre: Mediação, 2000.

LUCKESI, C. C. Avaliação da aprendizagem escolar. 18. ed. São Paulo: Cortez, 2006.

\begin{tabular}{|l|l|l|l|l|l|}
\hline Interface da Educ. & Paranaíba & v. 1 & n. 1 & p. 83-94 & 2010 \\
\hline
\end{tabular}


VIGOTSKI, L. S. Interação entre aprendizado e desenvolvimento. In:

. A formação Social da Mente: o desenvolvimento dos processos psicológicos superiores. 7. ed. São Paulo: Martins Fontes, 2008. (Psicologia e Pedagogia).

. Psicologia Pedagógica. 2. ed. São Paulo: Martins Fontes, 2004.

Acerca de los processos compensatórios en el desarrollo del niño mentalmente retrasado. In: _. Obras escogidas V: fundamentos de defectología. Madrid: Visor, 1997. (Aprendizaje). 